\title{
PENGEMBANGAN MODUL ASAM DAN BASA BERBASIS KONSTRUKTIVISME DI KELAS XI SMA
}

\section{Esty Suryani Putri *, Betty Holiwarni, Sri Haryati}

Program Studi Pendidikan Kimia, Fakultas Keguruan dan Ilmu Pendidikan Universitas Riau, Kampus Binawidya KM 12,5, Pekanbaru 28293, Riau, Indonesia

\begin{tabular}{l}
\hline \multicolumn{1}{c}{ Informasi Artikel } \\
\hline Sejarah Artikel: \\
Diterima: 20-05-2019 \\
Disetujui: 05-01-2021 \\
Dipublikasikan: 27-01-2021 \\
\hline Keywords: \\
module, \\
constructiivisme, \\
acid and base \\
learning media. \\
\hline
\end{tabular}

\begin{abstract}
A b s t r a k
Penelitian ini bertujuan untuk mengembangkan modul asam dan basa berbasis konstruktivisme yang valid dan praktis. Penelitian pengembangan ini menggunakan model 4-D yang memiliki empat tahap yaitu, define, design, develop dan disseminate, tetapi penelitian hanya sampai pada tahap Develop. Untuk menghasilkan modul yang valid diakukan uji validitas modul yang meliputi empat aspek penilaian, yaitu aspek kelayakan isi, aspek kebahasaan, aspek penyajian dan aspek kegrafisan. Untuk melihat kepraktisan modul dilakukan uji terbatas di SMAN 4 Pekanbaru dan SMAN 6 Pekanbaru. Hasil validasi oleh tiga validator menyatakan modul asam dan basa berbasis konstruktivisme valid dengan persentase rata-rata sebesar $91,8 \%$. Hasil angket uji terbatas 30 orang peserta didik adalah $97 \%$ dan hasil respons dari dua orang guru kimia adalah 90,62\%. Berdasarkan hasil validasi dan uji terbatas, modul asam dan basa berbasis konstruktivisme dinyatakan valid dan praktis.
\end{abstract}

\begin{abstract}
A b s tract
The study aims to develop acid and bases module Based on constructivism on Senior High School at Class XI that are valid and practical. This development reasearch uses a 4-D model that has four stages, namely, define, design, develop and disseminate, but research have conducted to development stage only. To produce a valid module, the module validity test is carried out which includes four aspects of assessment, namely aspects of content feasibility, linguistic aspects, presentation aspects and graphic aspects. to see the practicality of the module, limited testing were performed at SMAN 4 Pekanbaru and SMAN 6 Pekanbaru. The results of the study that have been validated by three validators state that the percentage is $91.8 \%$. The results of the test questionnaire were limited to 30 students, (97\%) and the results of the responses from two chemistry teachers were $90.62 \%$. Based on the principle of validation and limited testing, the acid and bases module based on constructivism was declared valid and practical.
\end{abstract}

\footnotetext{
*Alamat korespondensi:

e-mail: estiesp95@gmail.com

No. Telf: +625218969720
} 


\section{PENDAHULUAN}

Pendidikan merupakan usaha dasar dan terencana untuk mewujudkan suasana belajar dan proses pembelajaran agar peserta didik secara aktif mengembangkan potensi dirinya untuk memiliki kekuatan spiritual keagamaan, pengendalian diri, kecerdasan, akhlak mulia, serta keterampilan yang diperlukan dirinya, masyarakat, bangsa dan negara (UU No. 20 Tahun 2003). Pemerintah telah melakukan berbagai perubahan kebijakan dalam bidang pendidikan untuk meningkatkan kualitas pendidikan melalui implementasi Kurikulum 2013 yang lebih menitikberatkan kepada peserta didik untuk membangun pengetahuannya sendiri. Kurikulum 2013 tidak menghendaki pendidik menggunakan metode ceramah sebagai satu-satunya metode yang paling dominan dalam kegiatan pembelajaran akan tetapi peserta didik yang harusnya mengonstruksi pengetahuan bagi dirinya sendiri (Depdiknas, 2013). Permasalahan yang terdapat dalam dunia pendidikan Indonesia salah satunya adalah keterbatasan bahan ajar yang memfasilitasi peserta didik dalam membangun pengetahuan. Keterbatasan bahan ajar ini tentunya akan berpengaruh pada kualitas pembelajaran khususnya pembelajaran kimia (Devia et al., 2020.)

Berdasarkan analisis kebutuhan, maka peneliti melakukan analisis materi, wawancara dan memberikan angket kepada peserta didik dan guru kimia SMAN 6 Pekanbaru. Informasi yang diperolah dari analisis kebutuhan ditemukan bahwa penguasaan konsep peserta didik masih rendah, peserta menganggap kimia sebagai mata pelajaran sukar dipahami, khusus materi asam dan basa. hal ini disumbangkan oleh dalam proses pembelajaran lebih memfokuskan pada ketuntasan materi pelajaran dan proses pembelajaran. Disamping itu, bahan ajar yang digunakan peserta didik dalam proses pembelajaran hanya berupa buku cetak/teks. Buku teks yang digunakan belum mampu mendukung peserta didik untuk memahami dan membangun konsepnya sendiri dan penyajiannya yang monoton dan kurang menarik, sehingga peserta didik masih bersikap pasif dalam kegiatan pembelajaran yang menyebabkan kurangnya kebermaknaan pembelajaran bagi peserta didik.

Bahan ajar sangat penting bagi peserta didik dalam proses pembelajaran. Bahan ajar yang digunakan salah satunya adalah modul. Prastowo, (2012) menyatakan bahwa Modul merupakan bahan ajar yang disusun secara sistematis dengan bahasa yang mudah dipahami oleh peserta didik, sesuai usia dan tingkat pengetahuan mereka agar mereka dapat belajar secara mandiri dengan bimbingan minimal dari guru. Oleh karena itu modul dilengkapi dengan petunjuk belajar dan peserta didik dapat belajar secara mandiri dan tidak membutuhkan sumber yang banyak karena bahasa yang digunakan mudah dipahami. Modul yang akan dikembangkan haruslah memperhatikan perbedaan kecepatan dan kemampuan peserta didik dalam menerima materi pembelajaran. Pengembangan modul sebagai bahan ajar dapat memfasilitasi peserta didik dalam menemukan dan membangun pengetahuannya sendiri. Salah satu inovasi yang dapat dilakukan adalah dengan mengembangkan modul berbasis konstruktivisme.

Konstruktivisme merupakan landasan berpikir pembelajaran konstektual, yaitu bahwa pengetahuan dibangun oleh manusia sedikit demi sedikit yang hasilnya diperluas melalui konteks yang terbatas. Pembelajaran dengan menggunakan pendekatan konstruktivisme mampu mengajak peserta didik untuk berpikir dan mengonstruksi pengetahuan mereka sendiri melalui keterlibatan aktif peserta didik tersebut (Nurhadi, 2004). Pendekatan konstruktivisme digunakan untuk membantu peserta didik dalam belajar yaitu menghubungkan pengetahuan yang sudah dimiliki dengan konsep yang akan dipelajari sehingga menjadi pengetahuan baru. Tahapan konstruktivisme terdiri dari empat tahap, yaitu Apersepsi, Eksplorasi, Diskusi dan Penjelasan Konsep serta Aplikasi dan Pengembangan. Beberapa kajian secara konfrehensif mengeksplorasi tentang pengembangan modul berbasis konstruktivisme. Utami et al., (2018) telah mengembangkan modul keseimbangan kimia berbasis konstruktivisme menggunakan pendekatan lima Needahm dan kajian ini dikembangkan hanya sampai tahap validasi instrumen. Marsri, et al., (2015) telah melaporkan tentang pengembangan modul berbasis 
konstrukstivisme dan diaplikasi pada materi perhitungan kimia. Penelitian yang lain juga menginvestigasi tentang pengembangan modul berbasis konstruktivisme menggunakan lima fase Needham dan diterapkan pada materi lajur reaksi (Adawiyah, et al., 2019). Berdasarkan latar belakang diulas, maka penelitian ini bertujuan untuk mengembangkan modul berbasis konstruktivisme pada materi asam dan basa. Penelitian ini dijalankan di SMA 4 Pekanbaru.

\section{METODE PENELITIAN}

Penelitian dilaksanakan di Program Studi Pendidikan Kimia, Fakultas Keguruan dan Ilmu Pendidikan (FKIP) Universitas Riau. Waktu penelitian dilakukan mulai bulan September 2018 sampai dengan Maret 2019. Penelitian ini dirancang dengan desain Reserch and Development (R\&D) yang terdiri atas tiga tahap define, design, dan development yang mengacu pada model 4-D.

Instrumen data yang digunakan yaitu, lembar validasi ahli materi, lembar angket respons guru kimia dan lembar angket respons siswa. Skala penilaian yang digunakan pada angket validasi dan respons guru adalah skala Likert dengan skor 1-4, skala ini memberikan keleluasaan dalam menilai modul asam dan basa berbasis konstruktivisme. Hasil validitas dihitung dengan menggunakan persamaan 1:

$$
\text { Presentase }=\frac{\text { Skor yang diperoleh }}{\text { Skor maksimum }} \times 100 \%
$$

Kriteria dalam mengambil keputusan untuk validasi modul asam dan basa berbasis konstruktivisme dapat dilihat pada Tabel 1. Modul asam dan basa berbasis konstruktivisme dipakai jika penilaian rata-rata validator dikategorikan valid dan sangat valid.

Tabel 1. Kriteria kelayakan analisis persentase (Riduwan, 2012)

\begin{tabular}{|c|c|c|}
\hline No & Persentase $(\%)$ & Keterangan \\
\hline 1 & $80,00-100$ & (Riduwänaik/va)idid/Layak \\
\hline 2 & $60,00-79,99$ & Cukup Baik/Cukup Valid/Cukup Layak \\
\hline 3 & $50,00-59,99$ & Kurang Baik/Kurang Valid/Kurang Layak \\
\hline 4 & $0-49,99$ & Tidak Baik (Diganti) \\
\hline
\end{tabular}

Data lembar tanggapan peserta didik diperoleh setelah memberikan angket respons dengan menggunakan skala Guttman dengan pilihan jawaban iya dan tidak. Jawaban positif diberi nilai 1 dan 0 untuk jawaban negatif. Penentuan kriteria respons berdasarkan persentase yang diperoleh seperti pada Tabel 2.

Tabel 2. Kriteria tanggapan respons pengguna (Yumasari, 2010)

\begin{tabular}{lcc}
\hline No & Nilai $(\boldsymbol{\%})$ & Katergori \\
\hline 1 & $\geq 85.00$ & Sangat Positif/sangat baik \\
2 & $70.00-84.99$ & Positif/ baik \\
3 & $50.00-69.99$ & Kurang positif/ kurang baik \\
4 & $<50.00$ & Tidak positif/tidak baik \\
\hline
\end{tabular}




\section{HASIL DAN PEMBAHASAN}

Model yang digunakan dalam penelitian adalah model 4-D dengan yang meliputi tahap pendefinisian, perancangan, pengembangan. Setiap tahap pengembangan modul berbasis konstruktivisme dibahas secara terperinci sebagai berikut.

\section{A. Tahap Pendefinisian}

Hasil analisis ujung depan yaitu masih terbatasnya bahan ajar yang dapat memfasilitasi peserta didik dalam memahami konsep asam dan basa, serta membantu peserta didik membangun konsepnya secara mandiri.

Peserta didik pengguna modul memiliki rentang usia 15-17 tahun. Piaget menyatakan bahwa pada umur 15-17 tahun merupakan tahap operasional formal dan mendekati intelektual yang maksimal, namun karena kurangnya pengalaman sehingga membatasi pengetahuan dan kecakapannya untuk memanfaatkan apa yang dia ketahui.

Tahap selanjutnya adalah analisis tugas yang akan menghasilkan materi yang disajikan di dalam modul dan serta tahapan yang digunakan dalam penyajian modul sesuai dengan tuntutan silabus kurikulum K13, konsep-konsep utama yang akan dipelajari, serta indikator pencapaian kompetensi yang akan dicapai.

\section{B. Tahap Perancangan}

Dari analisis yang telah dilakukan, dilanjutkan dengan pembuatan outline modul berdasarkan aturan dari Depdiknas (2018). Hasil dari tahap design antara lain:

1. Rancangan pendahuluan modul

Pada rancangan pendahuluan modul menghasilkan: Kompetensi Dasar, Indikator Pencapaian Kompetensi, tujuan pembelajaran, deskripsi modul dan petunjuk penggunaan modul.

2. Pembelajaran

Pada bagian pembelajaran modul terdiri dari tahapan apersepsi, uraian materi, tahap eksplorasi, tahap diskusi dan penjelasan, tahap aplikasi dan pengembangan, rangkuman, penilaian diri, tugas/latihan, serta tes formatif dan umpan balik pada setiap kegiatan pembelajaran.

3. Penutup

Pada bagian penutup terdiri dari: evaluasi, glosarium, daftar pustaka, dan kunci jawaban tes formatif dan evaluasi.

\section{Tahap Pengembangan}

Pada tahap ini modul yang telah dikembangkan akan dilakukan proses validasi modul yang bertujuan untuk mengetahui tingkat kelayakan modul. Validasi dilakukan oleh tiga orang validator dengan aspek penilaian yang meliputi aspek kelayakan isi, kebahasaan, penyajian dan kegrafisan.

Validasi dilakukan beberapa kali sehingga diperoleh modul yang valid. Penilaian yang dilakukan oleh validator menghasilkan data nilai dari masing-masing aspek, rekap skor penilaian keempat aspek dapat dilihat pada Tabel 3. Skor rata-rata keseluruhan validasi modul asam dan basa berbasis konstruktivisme adalah 91,8\%. Berdasarkan kriteria kelayakan modul analisis persentase $91,8 \%$ termasuk kategori valid. 
Tabel 3 Rekap skor rata-rata penilaian keempat aspek kelayakan modul

\begin{tabular}{|c|c|c|c|c|c|c|}
\hline \multirow{2}{*}{$\begin{array}{l}\mathbf{N} \\
\mathbf{o}\end{array}$} & \multirow{2}{*}{$\begin{array}{l}\text { Aspek yang } \\
\text { dinilai }\end{array}$} & \multicolumn{4}{|c|}{ Nilai (\%) } & \multirow[t]{2}{*}{ Kategori } \\
\hline & & $\begin{array}{c}\text { Validator } \\
\text { I }\end{array}$ & $\begin{array}{c}\text { Validator } \\
\text { II }\end{array}$ & $\begin{array}{l}\text { Validator } \\
\text { III }\end{array}$ & $\begin{array}{c}\text { Jumlah rerata } \\
\text { validasi }\end{array}$ & \\
\hline 1. & $\begin{array}{l}\text { Kelayakan } \\
\text { Isi }\end{array}$ & 97.5 & 92.5 & 92.5 & 94.2 & Valid \\
\hline 2. & $\begin{array}{l}\text { Kelayakan } \\
\text { Kebahasaan }\end{array}$ & 90.0 & 90.0 & 95.0 & 90.0 & Valid \\
\hline 3. & $\begin{array}{l}\text { Kelayakan } \\
\text { Penyajian }\end{array}$ & 95.0 & 90.0 & 95.0 & 93.3 & Valid \\
\hline 4. & $\begin{array}{l}\text { Kelayakan } \\
\text { Kegrafisan }\end{array}$ & 90.0 & 95.0 & 85.0 & 90.0 & Valid \\
\hline \multicolumn{5}{|c|}{ Jumlah rerata validasi } & 91.8 & Valid \\
\hline
\end{tabular}

Lembar angket guru dan peserta didik digunakan untuk uji coba terbatas serta menilai tingkat keterpakaian modul yang dikembangkan. Persentase rata-rata respons guru dan peserta didik terhadap modul asam dan basa berbasis konstruktivisme di kelas XI SMA berturut-turut adalah 90,62\% dan 97\%. Mengacu pada Tabel 2 kriteria kelayakan tanggapan respons pengguna terletak ada rentang $\geq 85 \%$ dengan kategori sangat positif/sangat baik.

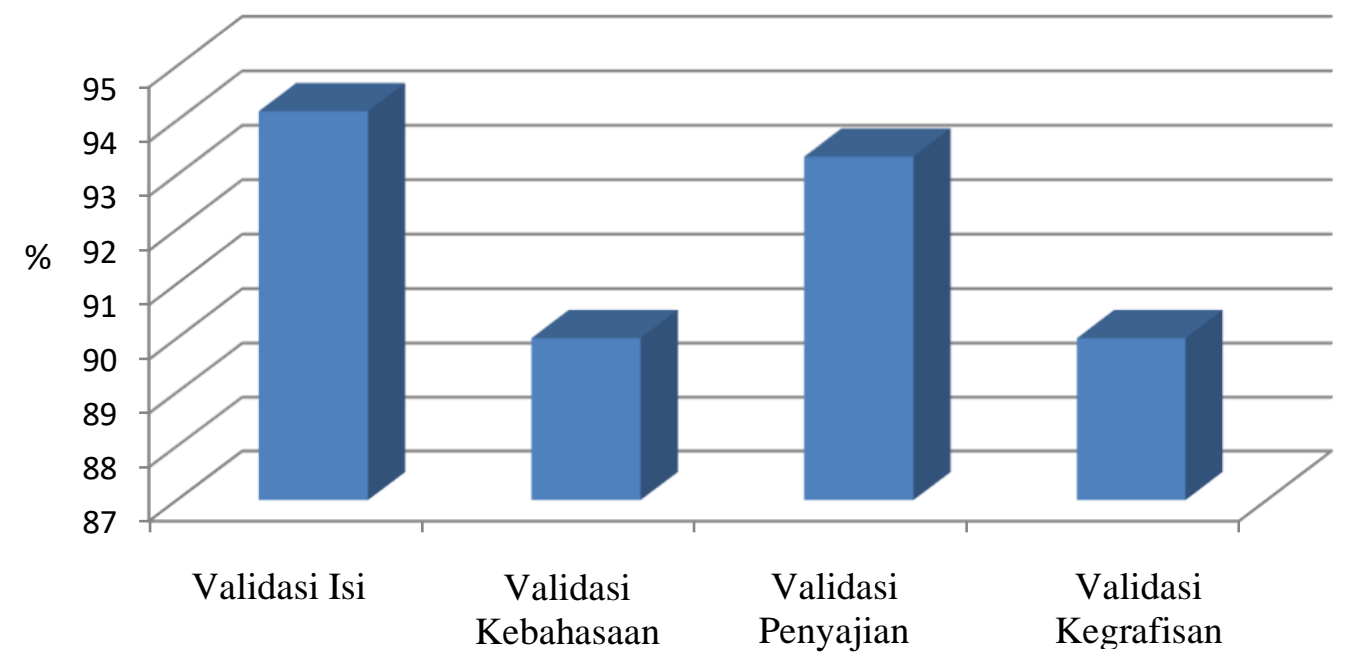

Gambar 1. Nilai rata-rata hasil validasi tiap aspek terhadap modul berbasis konstruktivisme

\section{KESIMPULAN}

\subsection{Kesimpulan}

Berdasarkan hasil penelitian dapat disimpulkan bahwa pengembangan modul asam dan basa berbasis konstruktivisme di kelas XI SMA dinyatakan valid aspek kelayakan isi, penyajian, kebahasaan, dan kegrafisan dengan. Skor rata-rata keseluruhan validasi modul adalah 91,8\% dengan kategori valid. Dan hasil uji respons guru dan peserta didik terhadap modul berturut-turut adalah 90,62\% dan 97\% dan dikategorikan sangat positif/sangat baik.

\subsection{Rekomendasi}

Pengembangan modul dikatakan berhasil apabila modul berstatus valid. Sedangkan modul yang dikembangkan ini baru melalui tahap menguji kevalidan modul. Oleh karena itu, modul dapat 
dilanjutkan dengan tahap uji coba produk, revisi produk, dan uji coba lapangan untuk mengumpulkan data yang dapat digunakan sebagai dasar menetapkan tingkat modul asam dan basa berbasis konstruktivisme di kelas XI SMA.

\section{DAFTAR PUSTAKA}

Adawiyah, R., Sukaryawan, M., Mujamil. J. 2019. Pengembangan modul laju reaksi berbasis konstruktivisme lima fase Needham. Jurnal Penelitian Pendidikan Kimia: Kajian Hasil Penelitian Pendidikan kimia. 6(1); 18-24.

Prastowo, A. 2012. Memahami Metode -Metode Penelitian. Ar-Ruzz Media. Yogyakarta.

Depdiknas, 2008. Panduan Pengembangan Bahan Ajar. Departemen Pendidikan Nasional Direktoral Jendral Manajemen Pendidikan Dasar dan Menengah Direktorat Pembinaan Sekolah Menengah Atas. Jakarta.

Depdiknas. 2013. Panduan Pengembangan Bahan Ajar. Direktorat Jenderal Manajemen Pendidikan Dasar dan Menengah, Departemen Pendidikan Nasional. Jakarta.

Devia, Y., Rery, R.U., Noer, A.M., Oktafianus. 2020. Pengembangan lembar kegiatan peserta didik hidrolisis garam berbasis hierarki konsep. Jurnal Pendidikan Kimia Universitas Riau. 5(1): 16-22.

Marsri, R., Ibrahim, A.R., Desi. 2015. Pengembangan modul perhitungan kimia berbasis konstruktivisme di kelas X sma negeri 1 tanjung batu. Jurnal Penelitian Pendidikan Kimia, 2(2): 134-143.

Riduwan. 2012. Skala Pengukuran Variabel-variabel Penelitian. Alfabeta. Bandung

Undang-Undang Nomor 20 Tahun 2003 Tentang Sistem Pendidikan Nasional. Citra Umbara. Jakarta.

Utami, B.T., Sukaryawan, M., Mujamil. J. 2018. Pengembangan modul kesetibambangan kimia berbasis konstruktivisme lima fase Needham. Jurnal Penelitian Pendidikan Kimia : Kajian Hasil Penelitian Kimia. 5(2): 114-125.

Yamasari, Y.2010. Pengembangan Media Pembelajaran Materi Berbasis ICT yang Berkualitas. Seminar Nasional Pascasarjana X-ITS. FMIPA UNESA. Surabaya. 